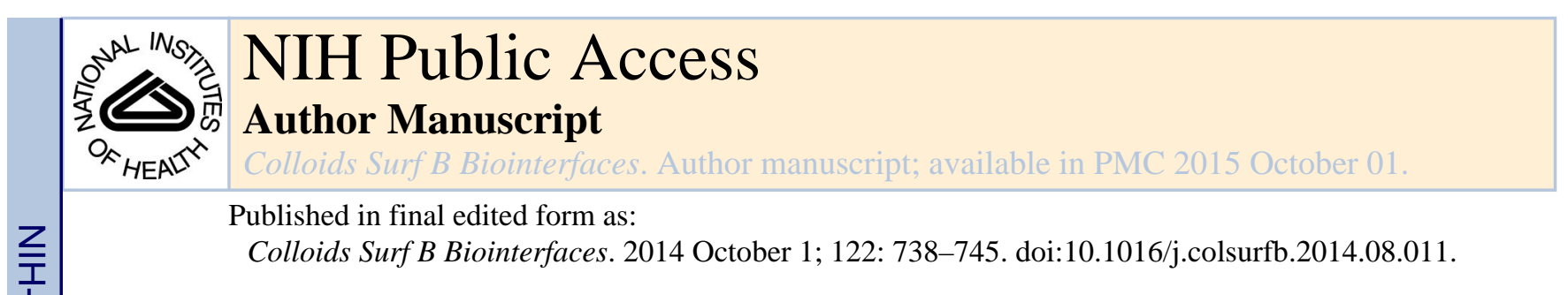

\title{
Polymeric Micelles for Acyclovir Drug Delivery
}

\author{
Alicia J. Sawdon and Ching-An Peng* \\ Department of Chemical Engineering, Michigan Technological University, Houghton, MI 49931
}

\begin{abstract}
Polymeric prodrug micelles for delivery of acyclovir (ACV) were synthesized. First, ACV was used directly to initiate ring-opening polymerization of $\varepsilon$-caprolactone to form $\mathrm{ACV}$ -

polycaprolactone (ACV-PCL). Through conjugation of hydrophobic ACV-PCL with hydrophilic methoxy poly(ethylene glycol) (MPEG) or chitosan, polymeric micelles for drug delivery were formed. ${ }^{1} \mathrm{H}$ NMR, FTIR, and gel permeation chromatography were employed to show successful conjugation of MPEG or chitosan to hydrophobic ACV-PCL. Through dynamic light scattering, zeta potential analysis, transmission electron microscopy, and critical micelle concentration $(\mathrm{CMC})$, the synthesized ACV-tagged polymeric micelles were characterized. It was found that the average size of the polymeric micelles was under $200 \mathrm{~nm}$ and the CMCs of ACV-PCLMPEG and ACV-PCL-chitosan were $2.0 \mathrm{mg} \mathrm{L}^{-1}$ and $6.6 \mathrm{mg} \mathrm{L}^{-1}$, respectively. The drug release kinetics of $\mathrm{ACV}$ was investigated and cytotoxicity assay demonstrates that ACV-tagged polymeric micelles were non-toxic.
\end{abstract}

\section{Keywords}

acyclovir; ring-opening polymerization; micellar drug delivery; methoxypolyethylene glycol; chitosan

\section{Introduction}

Due to the fact that nanoparticles can be prepared using a variety of polymers, biodegradable polymers have been extensively studied for the field of polymer therapeutics [1-3]. While there have been many biodegradable polymeric nanoparticles synthesized for drug delivery, polymeric micelles have numerous advantages over other proposed colloidal delivery systems [4-7]. Many studies have shown the promise micelles have for drug delivery because they can be tailored for prolonged blood circulation time, cellular selectivity, and for their controlled release capabilities [8-10]. In addition, micelles can be specifically synthesized to increase a drug's solubility and bioavailability [11-14].

\footnotetext{
(C) 2014 Elsevier B.V. All rights reserved.

* Corresponding author Department of Chemical Engineering Michigan Technological University 1400 Townsend Drive Houghton, MI 49931 Phone: 906-487-2569 cpeng@mtu.edu.

Publisher's Disclaimer: This is a PDF file of an unedited manuscript that has been accepted for publication. As a service to our customers we are providing this early version of the manuscript. The manuscript will undergo copyediting, typesetting, and review of the resulting proof before it is published in its final citable form. Please note that during the production process errors may be discovered which could affect the content, and all legal disclaimers that apply to the journal pertain.

Appendix A. Supplementary data
} 
Acyclovir (ACV) is a guanosine-based prodrug most commonly used for the treatment of infections caused by herpes simplex virus (HSV) type 1 and 2, varicella zoster virus and, to a lesser extent, cytomegalovirus and Epstein-Barr virus [15]. Moreover, prodrug ACV can be converted to its cytotoxic phosphorylated form by herpes simplex virus thymidine kinase (HSVTK) gene for cancer therapy [16]. That is, if the HSV-TK gene is delivered to actively dividing cancer cells, and ACV is subsequently administered to the cells, the TK enzyme phosphorylates ACV, yielding toxic metabolites which cause death in prodrug treated HSVTK expressing cells [17-19]. However, due to ACV's poor water solubility and ensuing low bioavailability, alternative delivery approaches are required to increase the therapeutic potential of ACV. Several methods reported are to couple ACV to biocompatible hydrophilic polymers [20-22] or encapsulation into drug carriers [23-25]. Although these processes increase the bioavailability of ACV as well as offer a practical treatment for patients, they are labor-intensive and cost- ineffective. Recently, we have shown that ACV can be used as an initiator to proceed ring-opening polymerization of $\varepsilon$-caprolactone ( $\varepsilon$-CL) to form hydrophobic ACV-polycaprolactone (ACV-PCL) [26], which makes this an economically attractive approach compared with the aforementioned conjugation and encapsulation methods.

Polymeric micelles consist of an inner core made of a hydrophobic block copolymer and an outer corona made of the hydrophilic block of the copolymer. PCL, having been widely used as the core-forming hydrophobic segment of nanoparticles, was selected as the model polymer for this study. PCL is a semi-crystalline, linear resorbable aliphatic polyester. It has been commonly used in drug delivery systems because it is biodegradable and biocompatible. [27-29] PCL is commonly synthesized by ring-opening polymerization of $\varepsilon$ CL using an alcohol as an initiator and stannous (II) octoate ( $\left.\mathrm{Sn}(\mathrm{Oct})_{2}\right)$ as a catalyst [30, 31]. In addition to using alcohol as the initiator, methoxy-poly(ethylene oxide) and starch have been employed as macroinitiators to form amphiphilic polymers. [32, 33]. In this study, prodrug ACV possessing hydroxyl groups was used as the initiator to obtain prodrug-PCL. Then, a hydrophilic compound (MPEG or chitosan) was grafted on the hydrophobic prodrug-PCL to form the amphiphilic block copolymer which already has the drug attached started from the ring-opening polymerization. These synthesized ACV-tagged amphiphilic polymers can self-assemble in aqueous medium to form polymeric prodrug micelles for use as nanocarriers in drug delivery.

Individual conjugation of ACV-PCL to a wide array of biocompatible hydrophilic polymers to form polymeric micelles each has their own advantages for drug delivery. With this in mind, we choose to assess the successful conjugation of two model hydrophilic polymers, MPEG and chitosan, to hydrophobic ACV-PCL. Chitosan is a natural polysaccharide derived from deacetylation of chitin. Chitosan's biocompatible and biodegradable features have attracted much attention in biomedical and pharmaceutical research [28, 34]. Similarly, MPEG is a biocompatible hydrophilic polymer commonly used in polymeric micelle formation. MPEG is inexpensive, non-toxic and is widely used to covalently modify biological macromolecules and surfaces [10, 35, 36]. Hence, ACV-PCL-MPEG and ACVPCL-chitosan copolymers were synthesized. The chemical structure and physical properties of the copolymers were characterized and micelle formation investigated. The drug release 
profiles of ACV from polymeric prodrug micelles and the biocompatibility of polymeric prodrug micelles were investigated in this study.

\section{Experimental Section}

\subsection{Materials}

ACV was purchased from TCI (Tokyo, Japan). N,N'-dicyclohexyl carbodiimide (DCC), $\varepsilon$ $\mathrm{CL}$, pyrene, and succinic anhydride were purchased from Acros Organics (Geel, Belgium). $\mathrm{Sn}(\mathrm{Oct})_{2}, \mathrm{CDCl}_{3}$ with $1 \%$ tetramethylsilane (TMS), deuterated dimethyl sulfoxide (DMSO$\mathrm{d}_{6}$ ), dimethyl sulfoxide (DMSO), tetrahydrofuran (THF), dichloromethane (DCM), methanol, 2-propanol, hexane, toluene, methoxypolyethylene glycol amine (MPEG- $\mathrm{NH}_{2}$; MW $=5,000)$, and chitosan oligosaccharide lactate (MW = 5,000) were all purchased from Sigma-Aldrich (St. Louis, MO). Ethyl ether was purchased from J.T. Baker (Austin, TX). NHydroxysuccinimide (NHS) was purchased from Alfa Aesar (Ward Hill, MA). Acetone was purchased from Pharmco-AAPER (Shelbyville, KY). Pyridine and hydrochloric acid $(\mathrm{HCl})$ were purchased from EMD (Philadelphia, PA). Sodium chloride $(\mathrm{NaCl})$ and magnesium sulfate were purchased from Showa (Tokyo, Japan). All reagents were used as received without further purification.

\subsection{Characterization Methods}

Gel permeation chromatography (GPC) analyses were performed on a Waters 1525 binary HPLC pump equipped with a Waters 2414 refractive index detector (Milford, MA). Waters styragel HR $3(\mathrm{MW}=500-30,000)$ and HR 4E (MW = $50-100,000)$ columns were equipped. Molecular weight calibration was performed with polystyrene standards that covered a MW range of $400-4.3 \times 10^{4}$. GPC analyses were performed in THF at a flow rate of $1 \mathrm{~mL} \mathrm{~min}{ }^{-1}$ with an injected volume of $50 \mu \mathrm{l} .{ }^{1} \mathrm{H}$ NMR spectra were obtained from a Varian Unity/Inova $400 \mathrm{MHz}$ instrument (Sparta, NJ). To obtain FTIR spectra by a Jasco FTIR-4200 spectrometer (Tokyo, Japan), a small amount of polymeric sample was loaded onto a silicon wafer and THF was added dropwise to dissolve the sample and evaporated afterwards. This was repeated until the entire sample was dissolved and a film had formed.

\subsection{Synthesis of ACV-tagged Amphiphilic Polymers}

2.3.1. Synthesis of ACV-PCL-ACV ( $50 \mathrm{mg}$ ) was weighed and mixed with $\varepsilon$-CL ( 2.25 $\mathrm{mL}$ ) under a sonication bath for $5 \mathrm{~min}$ at room temperature. $\mathrm{Sn}(\mathrm{Oct})_{2}(0.5 \mathrm{wt} \%$ of $\varepsilon-\mathrm{CL})$ was then added into the mixture. The entire solution was placed into a 3-necked round-bottom flask. The system was purged with nitrogen and immersed in an oil bath at $140^{\circ} \mathrm{C}$ for $24 \mathrm{~h}$. The crude product was cooled to room temperature, dissolved in DCM, and precipitated by cold methanol. The product was then vacuum dried by a rotary evaporator at $40^{\circ} \mathrm{C}$.

2.3.2. Synthesis of ACV-PCL-COOH-ACV-PCL ( $0.5 \mathrm{mmol})$ and succinic anhydride $(1 \mathrm{mmol})$ were weighed and dissolved in toluene in a 3-necked round-bottom flask. One mmol pyridine was added and the solution was reacted under nitrogen at $70^{\circ} \mathrm{C}$ for $48 \mathrm{~h}$. The product was then precipitated by cold hexane, and spun down. The pellet was re-dissolved in DCM and washed twice each with $10 \%$ (v/v) $\mathrm{HCl}$ and saturated $\mathrm{NaCl}$ solution. The organic phase was isolated and dried with magnesium sulfate then filtered. The carboxylated ACV- 
PCL was recovered by precipitation in cold hexane and then vacuum dried by rotary evaporation at $40^{\circ} \mathrm{C}$.

2.3.3. Synthesis of ACV-PCL-NHS-ACV-PCL-COOH ( $0.54 \mathrm{mmol})$ and NHS ( 2.7 mmol) were weighed and mixed in $15 \mathrm{~mL} \mathrm{DCM}$, and then DCC (2.7 mmol) was added. The reaction was run under a nitrogen environment at room temperature for $24 \mathrm{~h}$. The precipitated byproduct 1,3-dicyclohexylurea was removed by vacuum filtration. The filtrate was added into $35 \mathrm{~mL}$ diethyl ether and cooled to $4^{\circ} \mathrm{C}$ for $4 \mathrm{~h}$ to precipitate ACV-PCL-NHS. The precipitate was collected by centrifugation at 3,500 rpm for $5 \mathrm{~min}$, washed with 2propanol and solvent removed by rotary evaporation at $40^{\circ} \mathrm{C}$.

2.3.4. Synthesis of ACV-PCL-MPEG-ACV-PCL-NHS (10 mg) and MPEG-NH $\mathrm{N}_{2}(10$ $\mathrm{mg}$ ) were weighed and dissolved by $20 \mathrm{~mL}$ DCM in a round-bottom flask. The flask was purged with nitrogen and the solution was stirred for $24 \mathrm{~h}$. The solution was then dialyzed (MWCO $=6-8 \mathrm{kD}$, Spectra/Por, Rancho Dominguez, CA) against pure DCM to remove remaining MPEG-NH${ }_{2}$. ACV-PCL-MPEG was recovered by rotary evaporation at $40^{\circ} \mathrm{C}$.

2.3.5. Synthesis of ACV-PCL-chitosan-ACV-PCL-NHS (10 mg) was dissolved in 5 $\mathrm{mL}$ acetone and slowly added to chitosan solution (20 mg chitosan oligosaccharide lactate dissolved in $25 \mathrm{~mL}$ deionized water). The mixture, purged with nitrogen, was stirred in a round-bottom flask for $24 \mathrm{~h}$. The reacted solution was vacuum dried to remove acetone and then lyophilized. The amphiphilic polymer was then dissolved in DCM and dialyzed (MWCO $=6-8 \mathrm{kD}$, Spectra/Por) against pure DCM to remove unreacted chitosan. ACVPCL-chitosan was recovered by rotary evaporation at $40^{\circ} \mathrm{C}$.

\subsection{Preparation of Polymeric Prodrug Micelles}

ACV-PCL-MPEG and ACV-PCL-chitosan micelles were formed similarly. Briefly, $10 \mathrm{mg}$ of ACV-tagged amphiphilic polymer was dissolved in $2 \mathrm{~mL}$ acetone. The solution was then added dropwise to $10 \mathrm{~mL}$ deionized water under sonication. Acetone was removed by rotary evaporation and the final solution was collected by filtering through a $0.45 \mu \mathrm{m}$ filter.

\subsection{Determination of Critical Micelle Concentration}

The CMC was estimated by using pyrene as a fluorescent probe [37]. Briefly, $1 \mathrm{mg} \mathrm{mL}^{-1}$ of polymeric prodrug micelle was formed. Various amounts of deionized water and micellar solution were added respectively to glass vials to obtain micellar concentrations ranging from $5 \times 10^{-7}$ to $1 \mathrm{mg} \mathrm{mL}^{-1}$. Pyrene in acetone was then added separately to the prepared vials to get a final concentration of pyrene in water of $6.0 \times 10^{-7} \mathrm{mg} \mathrm{mL}^{-1}$, slightly lower than the saturation solubility of pyrene in water [38]. The solutions were then allowed to equilibrate for $8 \mathrm{~h}$. Fluorescent spectra were determined by a plate reader (Synergy MX, BioTek, Winooski, VT) with an excitation wavelength of $334 \mathrm{~nm}$.

\subsection{Size and Morphology of Polymeric Prodrug Micelles}

The average particle size of polymeric prodrug micelles was determined by a dynamic light scattering (DLS) instrument (Zetasizer Nano ZS, Malvern Instruments, United Kingdom) equipped with a red laser at a wavelength of $633 \mathrm{~nm}$ and scattering angle of $90^{\circ}$ at $25^{\circ} \mathrm{C}$. 
The zeta potential of the micelles dispersed in deionized water was determined with a zeta potential analyzer (Zetasizer Nano ZS). Transmission electron microscopy (TEM) image of micelles was performed on a JEM-4000FX (JEOL, Tokyo, Japan) at $80 \mathrm{kV}$. The TEM samples were prepared by adding $10 \mu \mathrm{L}$ of micellar solution $\left(1 \mathrm{mg} \mathrm{mL}^{-1}\right)$ onto a Formvar grid for $5 \mathrm{~min}$ and wicking away solution in excess. The samples were negatively stained with $10 \mu \mathrm{L}$ phosphotungstic acid solution ( $2 \mathrm{wt} \%$ ) for $10 \mathrm{sec}$ and then $15 \mathrm{sec}$, wicking away excess staining solution each time.

\subsection{Drug Release Kinetics}

Polymeric prodrug micelles at a concentration of $1 \mathrm{mg} \mathrm{mL}^{-1}$ were made in phosphate buffered saline (PBS) $(1 \mathrm{M}, \mathrm{pH} 7.4)$ at $25^{\circ} \mathrm{C}$. Two $\mathrm{mL}$ of solution was placed in a dialysis tube (Float-ALyzer, Spectra/Por) with a MWCO of $3.5-5 \mathrm{kD}$. The dialysis bag was then immersed in $50 \mathrm{~mL}$ PBS at room temperature. At specified time intervals, $5 \mu \mathrm{L}$ of sample was removed and replaced with fresh PBS. The amount of ACV released was analyzed by a plate reader (BioTek) at $254 \mathrm{~nm}$. All experiments were carried out in triplicate.

\subsection{Cytotoxicity Test}

24-well plates were seeded with human colorectal HT29 cells (HTB-38; ATCC, Manassas, VA) suspended in $0.5 \mathrm{~mL}$ Dulbecco's modified Eagles' medium (DMEM, Corning Cellgro, Manassas, VA) supplemented with $10 \%$ fetal bovine serum (FBS, Atlanta biologicals, Flowery Branch, GA) and $1 \%$ penicillin-streptomycin (Sigma) and incubated at $37^{\circ} \mathrm{C}$ in $5 \%$ $\mathrm{CO}_{2}$ balanced with humidified air for $24 \mathrm{~h}$. In each well, $500 \mu \mathrm{L}$ of $1 \mathrm{mg} \mathrm{mL}^{-1}$ ACV-PCLMPEG or ACVPCL-chitosan polymeric micelles (filtered by a $0.22 \mu \mathrm{m}$ filter) was added. After incubation for $48 \mathrm{~h}$, cell viability was assessed using MTT assay. $200 \mu \mathrm{L}$ of sterile MTT solution ( $4 \mathrm{mg} \mathrm{mL}^{-1}$ ) was added into the culture wells and incubated for $4 \mathrm{~h}$. The medium containing unreacted MTT was removed and $300 \mu \mathrm{L}$ DMSO was added to dissolve the insoluble purple formazan crystals formed in cellular mitochondria. The absorbance at $590 \mathrm{~nm}$ was measured with a plate reader (BioTek) and results were recorded as viability percentage calculated against the control group without micellar challenge. All experiments were carried out in triplicate.

\section{Results and Discussion}

\subsection{Synthesis and Characterization of Amphiphilic Prodrug Polymers}

ACV-PCL was synthesized through ring-opening polymerization of $\varepsilon$-CL, which was initiated exclusively by ACV (Scheme 1A). The number average molecular weight $\left(\mathrm{M}_{\mathrm{n}}\right)$ of ACV-PCL polymer after $24 \mathrm{~h}$ reaction time was approximately $1.7 \times 10^{4} \mathrm{~g} \mathrm{~mol}^{-1}$ with polydispersity index (PDI) of 1.64 as measured from GPC analysis (as shown in Table S1 in the supporting information). The ${ }^{1} \mathrm{H}$ NMR spectra of guanosine-based prodrug ACV and ACV-PCL $24 \mathrm{~h}$ post-synthesis are shown in Fig. S1(i) and (ii), respectively, in the supporting information. Judging from the ACV-PCL spectrum, chemical shifts at 3.75 (e, f$\left.\mathrm{CH}_{2}\right), 5.44\left(\mathrm{~d}-\mathrm{CH}_{2}\right), 7.68(\mathrm{~b}-\mathrm{CH})$ were assigned to protons in $\mathrm{ACV}$, while the peaks at $\delta=1.36\left(3-\mathrm{CH}_{2}\right), 1.64\left(2-\mathrm{CH}_{2}\right), 2.29\left(1-\mathrm{CH}_{2}\right)$ and $4.04\left(4-\mathrm{CH}_{2}\right)$ correspond with the backbone chain of PCL polymer. The characteristic resonances of PCL and ACV were both observed in the synthesized polymer. Although the characteristic peaks of ACV in Fig. 
S1(ii) are much lower than those representing PCL, the evidence of coupling of ACV's protons in synthesized ACV-PCL is clear.

ACV-PCL was further conjugated with either MPEG or chitosan as shown in scheme 1 B-E. Successful conjugation of MPEG or chitosan was confirmed by GPC, ${ }^{1} \mathrm{H}$ NMR and FTIR analyses. The increase in $\mathrm{M}_{\mathrm{n}}$ of ACV-PCL to $22.4 \mathrm{kDa}$ from $17.5 \mathrm{kDa}$ corresponds with the addition of MPEG (Table $\mathrm{S} 1$ in the supporting information). Fig. 1 shows the ${ }^{1} \mathrm{H}$ NMR of MPEG-NH $\mathrm{N}_{2}$ and ACV-PCL-MPEG. The peak at $3.63\left(\mathrm{~A}-\mathrm{OCH}_{2}\right)$ attributed to MPEG can be clearly seen in Fig. 1 (iv). Due to the conjugation of MPEG to ACV-PCL though amide linkage (Scheme 1D), the change of the peak at $1.79\left(\mathrm{~B}-\mathrm{NH}_{2}\right)$ from a singlet in Fig. 1 (iii) to a multiplet in Fig. 1 (iv) further confirms conjugation of MPEG to ACV-PCL. Further characterization of successful grafting of MPEG to hydrophobic ACV-PCL was examined through FTIR analysis. FTIR spectra of ACV-PCL (A), MPEG-NH 2 (B) and ACV-PCLMPEG (C) are shown in Fig. 2. C-H stretching vibrations can be seen from $2945-2852 \mathrm{~cm}^{-1}$ for all samples. The typical bending vibration of $1634 \mathrm{~cm}^{-1}$ for the $\mathrm{NH}_{2}$ bending amide I band can be seen in ACV-PCL and ACVPCL-MPEG spectra, and is attributed to ACV. PCL and MPEG blocks were characterized by prominent absorptions at $1726 \mathrm{~cm}^{-1}(\mathrm{C}=\mathrm{O})$ and $1112 \mathrm{~cm}^{-1}$ (C-O-C), respectively. These peaks are found in ACV-PCL-MPEG copolymer ascertaining successful bonding of MPEG to ACV-PCL.

GPC analysis revealed that the $\mathrm{M}_{\mathrm{n}}$ of ACV-PCL increased from $17.5 \mathrm{kDa}$ to $21.7 \mathrm{kDa}$ after grafting with chitosan and had a PDI of 1.42 (Table $\mathrm{S} 1$ in the supporting information). Successful conjugation of chitosan to ACV-PCL was characterized similar to ACV-PCLMPEG. Fig. 3 reveals the ${ }^{1} \mathrm{H}$ NMR of chitosan (v) and ACV-PCL-chitosan (vi). As shown in Scheme 1E, conjugation of chitosan to ACV-PCL is made via amide linkage. The peak at $1.79\left(\mathrm{~A}-\mathrm{NH}_{2}\right)$ from a singlet to a multiplet in Fig. 3 (vi) confirms conjugation of chitosan to ACV-PCL. Moreover, the peaks from the aromatic protons on $\mathrm{C}_{3}-\mathrm{C}_{6}$ can be seen from $\delta=$ $3.28-3.85$, slightly shifted downward from the peaks shown in the original chitosan sample. Fig. 4 depicts the FTIR spectra of ACV-PCL (A), chitosan (B), and ACV-PCLchitosan (C). $\mathrm{OH}$ stretching from $3429-3167 \mathrm{~cm}^{-1}$ as well as peaks at $1634 \mathrm{~cm}^{-1}$ and 1521 $\mathrm{cm}^{-1}$ corresponding to the $\mathrm{N}-\mathrm{H}$ bending vibrations of the amide I and II bands are attributed to ACV and chitosan, respectively. The aforementioned peaks as well as the carbonyl absorption at $1726 \mathrm{~cm}^{-1}$ associated with PCL and a peak at $1065 \mathrm{~cm}^{-1}$ (C-O-C) seen in each spectra are found in ACV-PCL-chitosan. The FTIR results are in line with the results from ${ }^{1} \mathrm{H}$ NMR and demonstrate successful synthesis of ACV-PCL-chitosan.

\subsection{Formation and Characterization of ACV-tagged Polymeric Micelles}

Due to the amphiphilic nature of the synthesized ACV-PCL copolymers (i.e., ACV-PCLMPEG and ACV-PCL-chitosan), they can self-assemble into polymeric prodrug micelles in aqueous medium. Here, ACV-PCL acts as the hydrophobic segment and MPEG or chitosan serve as the hydrophilic segments. Polymeric micelles of ACV-PCL copolymer were prepared via the evaporation method [39]. The CMC using pyrene as a hydrophobic fluorescent probe was carried out to prove the formation of the micellar structures. Pyrene can preferentially partition into the interior hydrophobic microdomains and change the intensities of the first and third bands in the pyrene fluorescence spectrum [38] For ACV- 
PCL-MPEG the shift found in the first and third bands was at $\mathrm{I}_{335} / \mathrm{I}_{330}$ while for ACV-PCLchitosan it was at $\mathrm{I}_{337} / \mathrm{I}_{332}$. It is believed that this change is due to different polymer compositions. Fig. 5A shows the CMC values of ACV-tagged polymeric micelles in aqueous medium. It was determined that the CMCs for ACV-PCL-MPEG and ACV-PCLchitosan were 2.0 and $6.6 \mathrm{mg} \mathrm{L}^{-1}$, respectively (Fig. 5A (i) and (ii)). Kim et al. reported that the CMC values of block copolymers depends upon the block copolymer architecture [40]. In this study, the hydrophobic block was kept constant, as ACV-PCL, while the hydrophilic block was changed to either MPEG or chitosan. The low CMC value obtained for ACVtagged polymeric micelles could provide evidence for their stability in dilute solutions.

In order to characterize the morphology of ACV-tagged polymeric micelles, DLS and TEM analyses were carried out. Fig. 5B shows the size and morphology of ACV-tagged polymeric micelles. As can be seen from DLS results, sizes of the two types of polymeric prodrug micelles were under $200 \mathrm{~nm}$. ACV-PCL-MPEG (Fig. 5B (i)) and ACV-PCLchitosan (Figure 5B (ii)) micelles showed size distributions with mean diameters of 141.8 and $172.7 \mathrm{~nm}$, respectively. The morphology of the micelles was further examined by TEM as shown in the insets of Fig. 5B. The size of the micelles in the TEM images was slightly lower than the results from DLS with an average particle size of $\sim 100-150 \mathrm{~nm}$. This size fluctuation is due to the fact that DLS records the hydrodynamic radius of particles which is often times slightly larger than the actual particle size. Zeta potential analysis of ACVtagged polymeric micelles was also performed. An average zeta potential for ACV-PCLMPEG micelles was $1.4 \mathrm{mV}$. Due to the fact that MPEG has a neutral charge, the results obtained for ACV-PCL-MPEG micelles are reasonable. In contrast, the detected zeta potential of ACV-PCL-chitosan micelles was $32.3 \mathrm{mV}$. This is attributed to the positive charge of the hydrophilic chitosan segment deployed on micellar nanoparticles.

To determine the drug loading percentage of acyclovir per mg of micelle formulation, the absorbance of ACV-tagged polymeric micelles at $\mathrm{t}=0$ and $\mathrm{t}=48 \mathrm{~h}$ was examined and compared to a standard calibration curve of ACV ranging from 0.002 to $1.0 \mathrm{mg} / \mathrm{mL}$. It was found that ACV comprised $8.7 \%$ and 3.2\% of ACV-PCL-MPEG and ACV-PCL-chitosan micelles, respectively. The difference in ACV loading percentage is due to different conditions employed for the synthesis of ACV-PCL-MPEG and ACV-PCL-chitosan amphiphilic copolymers. While $\mathrm{MPEGNH}_{2}$ can dissolve in organic solvent, chitosan requires an aqueous solvent for it to dissolve. Therefore, for ACV-PCL-chitosan synthesis, the ester bond between ACV and PCL is already weakened, thereby resulting in less ACV coupled with PCL than ACV-PCL-MPEG which is synthesized under organic solvent environment.

\subsection{In Vitro Release of ACV from Polymeric Micelles}

The in vitro release behaviors of $\mathrm{ACV}$ from both types of polymeric prodrug micelles in $\mathrm{PBS}$ at $25^{\circ} \mathrm{C}$ were studied and the results are shown in Fig. 6. Similar biphasic drug release profile of ACV-PCL-MPEG and ACV-PCL-chitosan micelles was observed, with initial burst release within the first $2 \mathrm{~h}(\sim 50 \%$ accumulative release) followed by a sustained release pattern up to $48 \mathrm{~h}$. The release of ACV from both polymeric prodrug micelles was caused by the hydrolysis of ester linkage between ACV and PCL. In the first phase, the rate 
of drug release from ACV-PCL MPEG micelles was relatively rapid than that from ACVPCL-chitosan ones. The reason for this phenomenon is speculated to be twofold. First, MPEG chains probably are more hydrophilic and flexible than chitosan chains on micellar nanoparticles, leading to a faster hydrolysis and concomitant ACV diffusion from hydrophobic PCL cores. Second, the diffusion of ACV molecules might be slowed down by the positively charged chitosan on ACV-PCL-chitosan micelles. Such different initial release trend continued and resulted in higher ACV accumulative release from ACV-PCLMPEG micelles (96\%) than from ACV-PCL-chitosan micelles (82\%).

\subsection{Cytotoxicity Study}

Biocompatibility is a vital necessity of polymer materials being used for drug delivery applications. To evaluate if ACV-tagged polymeric micelles showed any cytotoxicity towards HT29 colorectal cells, MTT assay was performed. As shown in Fig. 7, the viability of HT29 cells after treatment for $48 \mathrm{~h}$ with either ACV-PCL-MPEG or ACV-PCL-chitosan has little change compared with the untreated control cells (i.e., cells without any micelle challenge). These results demonstrate that ACV-tagged polymeric micelles do not exhibit apparent toxicity, and are biocompatible.

\section{Conclusion}

In this study, ACV-PCL-MPEG and ACV-PCL-chitosan polymeric micelles were synthesized and characterized. ACV was used to directly initiate polymerization of $\varepsilon$-CL to form hydrophobic ACV-PCL. Compared to conventional methods of incorporating ACV into polymeric carriers by chemical conjugation or physical encapsulation, our approach is advantageous in terms of eliminating drug-loading steps, enhancing drug-carrying capacity, and decreasing production cost. By grafting ACV-PCL with either MPEG or chitosan, ACV-tagged amphiphilic polymers can self-assemble as micellar nanoparticles in aqueous medium. Structural analyses such as ${ }^{1} \mathrm{H}$ NMR and FTIR were performed to confirm their conjugation. ACV-tagged polymeric micelles were found to have a mean size under $200 \mathrm{~nm}$ by both DLS and TEM and have a low CMC. Moreover, both ACV-PCL-MPEG and ACVPCL-chitosan micelles were nontoxic to HT29 colorectal cells. ACV-tagged polymeric micelles are potential carriers for therapeutic and anticancer drug delivery.

\section{Supplementary Material}

Refer to Web version on PubMed Central for supplementary material.

\section{References}

1. Corden TJ, Jones IA, Rudd CD, Christian P, Downes S, McDougall KE. Physical and biocompatibility properties of poly- $\varepsilon$-caprolactone produced using in situ polymerisation: a novel manufacturing technique for long-fibre composite materials. Biomaterials. 2000; 21:713-724. [PubMed: 10711968]

2. Duncan R, Vicent MJ. Polymer therapeutics-prospects for 21st century: The end of the beginning. Adv. Drug Deliv. Rev. 2013; 65:60-70. [PubMed: 22981753]

3. Guan X, Quan D, Shuai X, Liao K, Mai K. Chitosan-graft-poly( $\varepsilon$-caprolactone)s: An optimized chemical approach leading to a controllable structure and enhanced properties. J. Appl. Polym. Sci. 2007; 45:2556-2568. 
4. Soppimath KS, Aminabhavi TM, Kulkarni AR, Rudzinski WE. Biodegradable polymeric nanoparticles as drug delivery devices. J. Control. Release. 2001; 70:1-20. [PubMed: 11166403]

5. Kalachandra S, Takamata T, Lin D, Snyder E, Webster-Cyriaque J. Stability and release of antiviral drugs from ethylene vinyl acetate (EVA) copolymer. J. Mater. Sci. Mater. Med. 2006; 17:12271236. [PubMed: 17143753]

6. Zhang C, Ding Y, Ping Q, Yu L. Novel chitosan-derived nanomaterials and their micelle-forming properties. J. Agric. Food Chem. 2006; 54:8409-8416. [PubMed: 17061814]

7. Torchilin V. Micellar nanocarriers: Pharmaceutical perspectives. Pharm. Res. 2007; 24:1-16. [PubMed: 17109211]

8. Kataoka K, Harada A, Nagasaki Y. Block copolymer micelles for drug delivery: design, characterization and biological significance. Adv. Drug Deliv. Rev. 2001; 47:113-131. [PubMed: 11251249]

9. Ashok B, Arleth L, Hjelm RP, Rubinstein I, Önyüksel H. In vitro characterization of PEGylated phospholipid micelles for improved drug solubilization: Effects of PEG chain length and PC incorporation. J. Pharm. Sci. 2004; 93:2476-2487. [PubMed: 15349957]

10. Tabatabaei Rezaei SJ, Nabid MR, Niknejad H, Entezami AA. Multifunctional and thermoresponsive unimolecular micelles for tumor-targeted delivery and site-specifically release of anticancer drugs. Polymer. 2012; 53:3485-3497.

11. del Amo EM, Urtti A. Current and future ophthalmic drug delivery systems: A shift to the posterior segment. Drug Discov. Today. 2008; 13:135-143. [PubMed: 18275911]

12. Nakanishi T, Fukushima S, Okamoto K, Suzuki M, Matsumura Y, Yokoyama M, Okano T, Sakurai Y, Kataoka K. Development of the polymer micelle carrier system for doxorubicin. J. Control. Release. 2001; 74:295-302. [PubMed: 11489509]

13. Yokoyama M, Miyauchi M, Yamada N, Okano T, Sakurai Y, Kataoka K, Inoue S. Polymer micelles as novel drug carrier-adriamycin-conjugated poly(ethylene glycol) poly(asparic acid) block copolymer. J. Control. Release. 1990; 11:269-278.

14. Koizumi F, Kitagawa M, Negishi T, Onda T, Matsumoto S-I, Hamaguchi T, Matsumura Y. Novel SN-38-incorporating polymeric micelles, NK012, eradicate vascular endothelial growth factorsecreting bulky tumors. Cancer Res. 2006; 66:10048-10056. [PubMed: 17047068]

15. Richards DM, Carmine AA, Brogden RN, Heel RC, Speight TM, Avery GS. Acyclovir a review of its pharmacodynamic properties and therapeutic efficacy. Drugs. 1983; 26:378-438. [PubMed: 6315332]

16. Moolten FL, Wells JM. Curability of tumors bearing herpes thymidine kinase genes transfered by retroviral vectors. J. Natl. Cancer Inst. 1990; 82:297-300. [PubMed: 2299679]

17. Cheon J, Kim HK, Moon DG, Yoon DK, Cho JH, Koh SK. Adenovirus-mediated suicide-gene therapy using the herpes simplex virus thymidine kinase gene in cell and animal models of human prostate cancer: changes in tumour cell proliferative activity. BJU Int. 2000; 85:759-766. [PubMed: 10759680]

18. Chen SH, Shine HD, Goodman JC, Grossman RG, Woo SL. Gene therapy for brain tumors: Regression of experimental gliomas by adenovirus-mediated gene transfer in vivo. Proc. Natl. Acad. Sci. U.S.A. 1994; 91:3054-3057. [PubMed: 8159705]

19. Fillat C. Suicide gene therapy mediated by the herpes simples virus thymidine kinase gene/ ganciclovir system: Fifteen years of application. Curr. Gene Ther. 2003; 3:13-26. [PubMed: 12553532]

20. Li X, Lu M, Wu Q, Lv DS, Lin XF. Novel designed polymer-acyclovir conjugates with linkercontrolled drug release and hepatoma cell targeting. J. Appl. Polym. Sci. 2008; 46:117-126.

21. Tu J, Zhong S, Li P. Studies on acyclovir-dextran conjugate: Synthesis and pharmacokinetics. Drug Dev. Ind. Pharm. 2004; 30:959-965. [PubMed: 15554220]

22. Zacchigna M, Di Luca G, Maurich V, Boccù E. Syntheses, chemical and enzymatic stability of new poly(ethylene glycol)-acyclovir prodrugs. Il Farmaco. 2002; 57:207-214. [PubMed: 11989799]

23. Genta I, Conti B, Perugini P, Pavanetto F, Spadaro A, Puglisi G. Bioadhesive microspheres for ophthalmic administration of acyclovir. J. Pharm. Pharmacol. 1997; 49:737-742. [PubMed: 9379347] 
24. Tao Y, Lu Y, Sun Y, Gu B, Lu W, Pan J. Development of mucoadhesive microspheres of acyclovir with enhanced bioavailability. Int.J. Pharm. 2009; 378:30-36. [PubMed: 19465102]

25. Jain SK, Gupta Y, Jain A, Rai K. Enhanced transdermal delivery of acyclovir sodium via elastic liposomes. Drug Deliv. 2008; 15:141-147. [PubMed: 18379926]

26. Sawdon A, Peng CA. Guanosine-based antiviral acyclovir incorporated in ring-opening polymerization of $\varepsilon$-caprolactone. Macromol. Res. 2012:1-5.

27. Li YY, Zhang XZ, Cheng H, Zhu JL, Cheng SX, Zhuo RX. Self-assembled, thermosensitive PCLg-P(NIPAAm-co-HEMA) micelles for drug delivery. Macromol. Rapid Commun. 2006; 27:19131919.

28. Sinha VR, Singla AK, Wadhawan S, Kaushik R, Kumria R, Bansal K, Dhawan S. Chitosan microspheres as a potential carrier for drugs. Int. J. Pharm. 2004; 274:1-33. [PubMed: 15072779]

29. Dash TK, Konkimalla VB. Poly- $\varepsilon$-caprolactone based formulations for drug delivery and tissue engineering: A review. J. Control. Release. 2012; 158:15-33. [PubMed: 21963774]

30. Peng CL, Shieh MJ, Tsai MH, Chang CC, Lai PS. Self-assembled star-shaped chlorin-core poly( $\varepsilon$ caprolactone)-poly(ethylene glycol) diblock copolymer micelles for dual chemo-photodynamic therapies. Biomaterials. 2008; 29:3599-3608. [PubMed: 18572240]

31. Schindler A, Hibionada YM, Pitt CG. Aliphatic polyesters. III. Molecular weight and molecular weight distribution in alcohol-initiated polymerizations of $\varepsilon$-caprolactone. J. Pol. Sci. 1982; 20:319-326.

32. Aliabadi HM, Mahmud A, Sharifabadi AD, Lavasanifar A. Micelles of methoxy poly(ethylene oxide)-b-poly( $\varepsilon$-caprolactone) as vehicles for the solubilization and controlled delivery of cyclosporine A. J. Control. Release. 2005; 104:301-311. [PubMed: 15907581]

33. Dubois P, Krishnan M, Narayan R. Aliphatic polyester-grafted starch-like polysaccharides by ringopening polymerization. Polymer. 1999; 40:3091-3100.

34. Sonia, T.; Sharma, C. Chitosan and its derivatives for drug delivery perspective, in: Chitosan for Biomaterials I. Jayakumar, R.; Prabharan, M.; Muzzarelli, R., editors. Springer; Berlin: 2011. p. 23-53.

35. Kang JS, Deluca PP, Lee KC. Emerging PEGylated drugs. Expert Opin. Emerg. Drugs. 2009; 14:363-380. [PubMed: 19453284]

36. Calvo P, Gouritin B, Brigger I, Lasmezas C, Deslys J-P, Williams A, Andreux JP, Dormont D, Couvreur P. PEGylated polycyanoacrylate nanoparticles as vector for drug delivery in prion diseases. J. Neurosci. Methods. 2001; 111:151-155. [PubMed: 11595281]

37. Wilhelm M, Zhao CL, Wang Y, Xu R, Winnik MA, Mura JL, Riess G, Croucher MD. Poly(styrene-ethylene oxide) block copolymer micelle formation in water: a fluorescence probe study. Macromolecules. 1991; 24:1033-1040.

38. Kalyanasundaram K, Thomas JK. Environmental effects on vibronic band intensities in pyrene monomer fluorescence and their application in studies of micellar systems. J. Am. Chem. Soc. 1977; 99:2039-2044.

39. Lu XY, Wu DC, Li ZJ, Chen GQ. Polymer nanoparticles. Prog. Mol. Biol. Transl. Sci. 2011; 104:299-323. [PubMed: 22093222]

40. Kim KH, Cui GH, Lim HJ, Huh J, Ahn CH, Jo WH. Synthesis and micellization of star-shaped poly(ethylene glycol)-block-poly(e-caprolactone). Macromol. Chem. Physics. 2004; 205:16841692. 


\section{Highlights}

- Acyclovir was used directly to initiate polymerization of $\varepsilon$-caprolactone.

- ACV-tagged micelles were self-assembled by conjugation with hydrophilic poly(ethylene glycol) or chitosan.

- $\quad$ ACV-tagged polymeric micelles are non-toxic.

- $\quad$ ACV-tagged micelles are advantageous in terms of eliminating drug-loading steps, enhancing drug-carrying capacity, and decreasing production cost. 
A<smiles>CC(C)OCCCCCC(=O)OCCOCn1cnc2c(=O)[nH]c(N)nc21</smiles>

B<smiles>CC(C)COCCOCn1cnc2c(=O)[nH]c(N)nc21</smiles>

$\mathrm{C}$<smiles>O=C1CCC(=O)N1O</smiles><smiles>CC(=O)OCCOCn1cnc2c(=O)[nH]c(N)nc21</smiles>

D

3

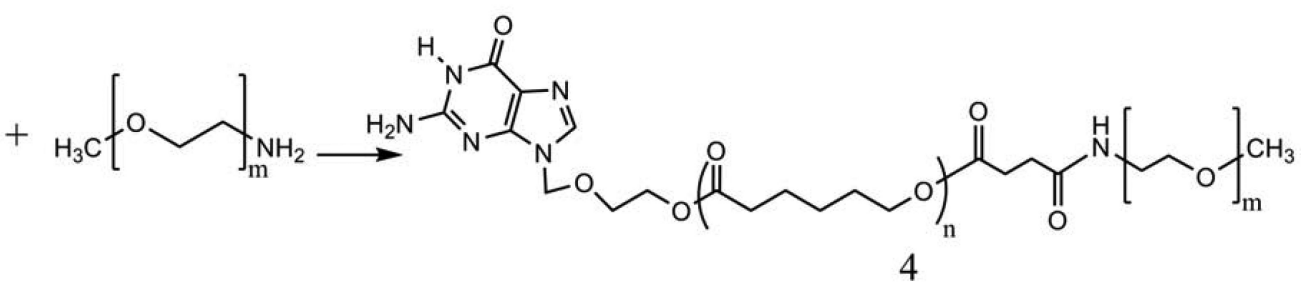

E

$3+$

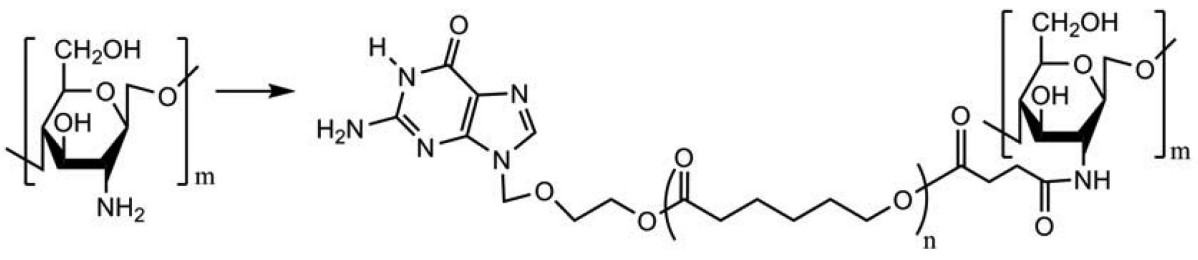

5

Scheme 1.

Synthetic scheme of (A) ACV-PCL, (B) ACV-PCL-COOH, (C) ACV-PCL-NHS, (D) ACVPCL-MPEG, and (E) ACV-PCL-chitosan. 


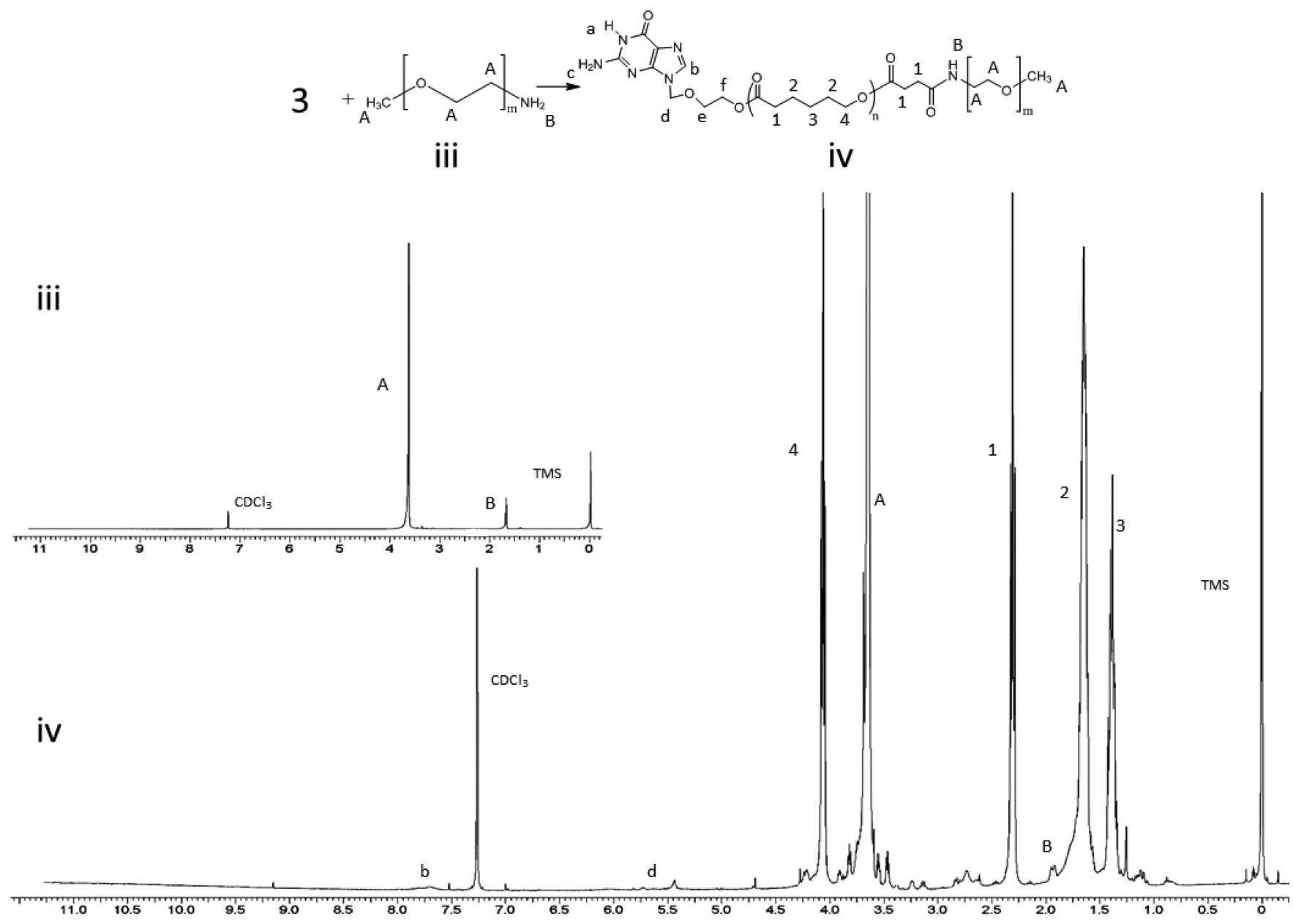

Fig. 1.

${ }^{1} \mathrm{H}$ NMR spectra of (iii) MPEG and (iv) ACV-PCL-MPEG. 


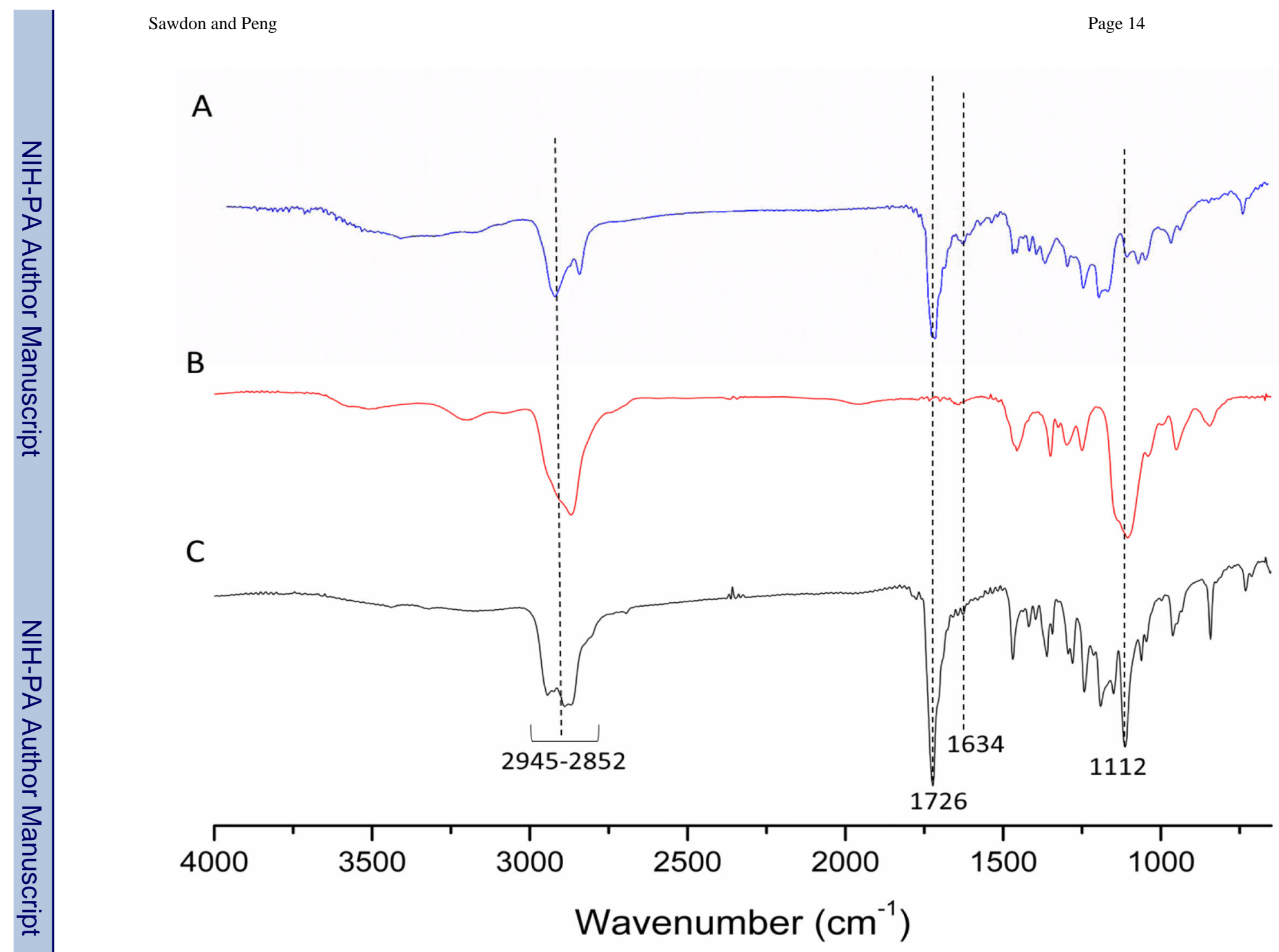

Fig. 2.

FTIR spectra of (A) ACV-PCL, (B) MPEG-NH 2 , and (C) ACV-PCL-MPEG. 

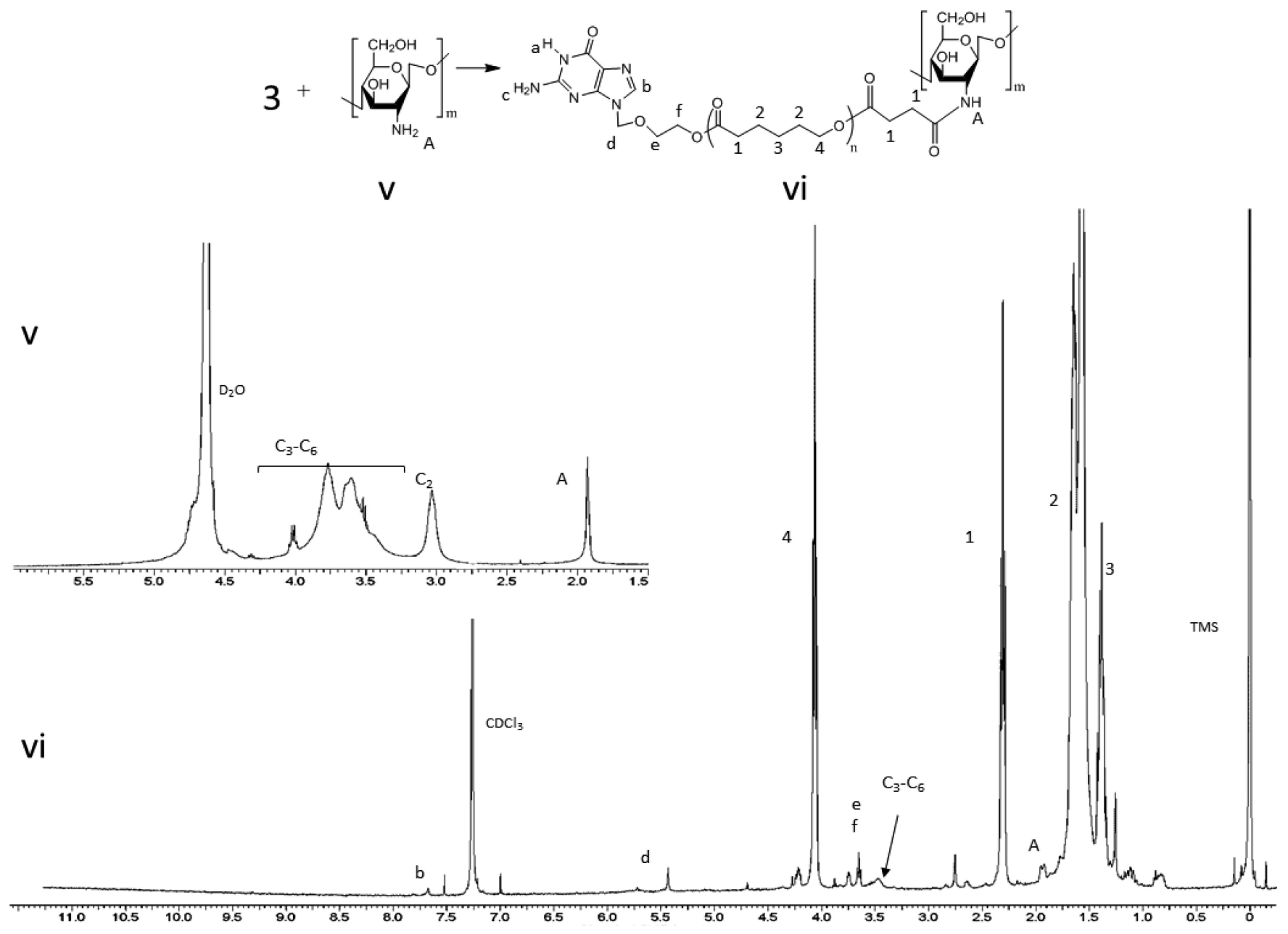

Fig. 3.

${ }^{1} \mathrm{H}$ NMR spectra of (v) chitosan and (vi) ACV-PCL-chitosan. 


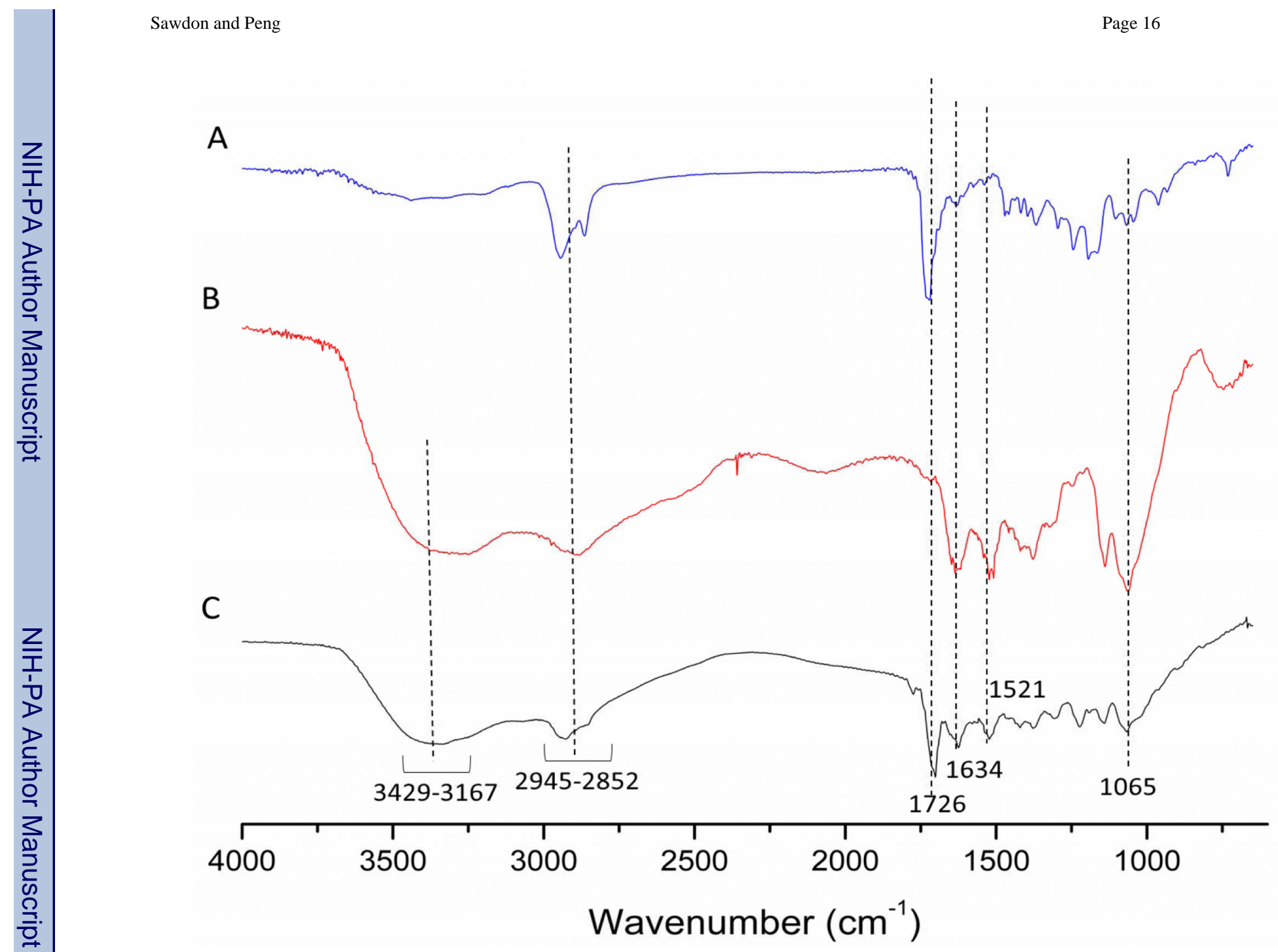

Fig. 4.

FTIR spectra of (A) ACV-PCL, (B) chitosan, and (C) ACV-PCL-chitosan. 


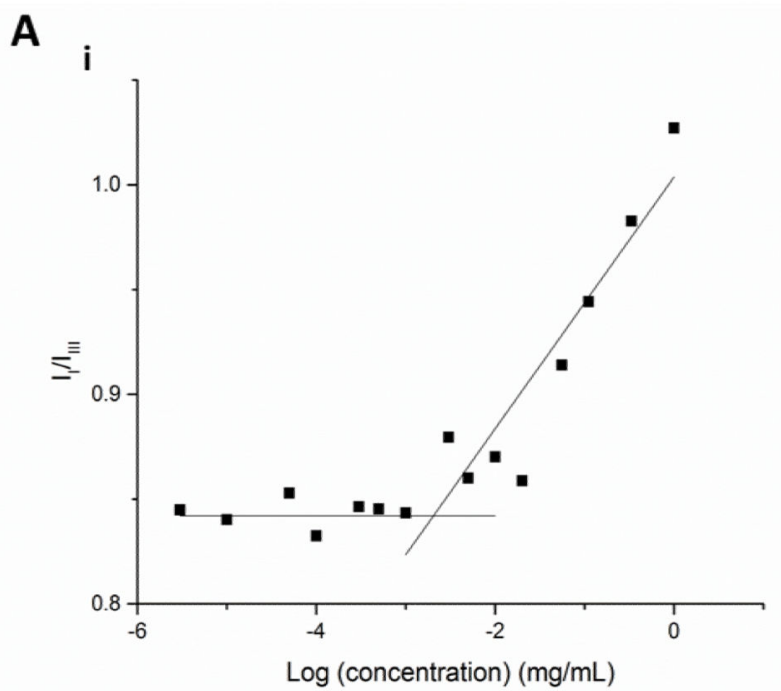

B

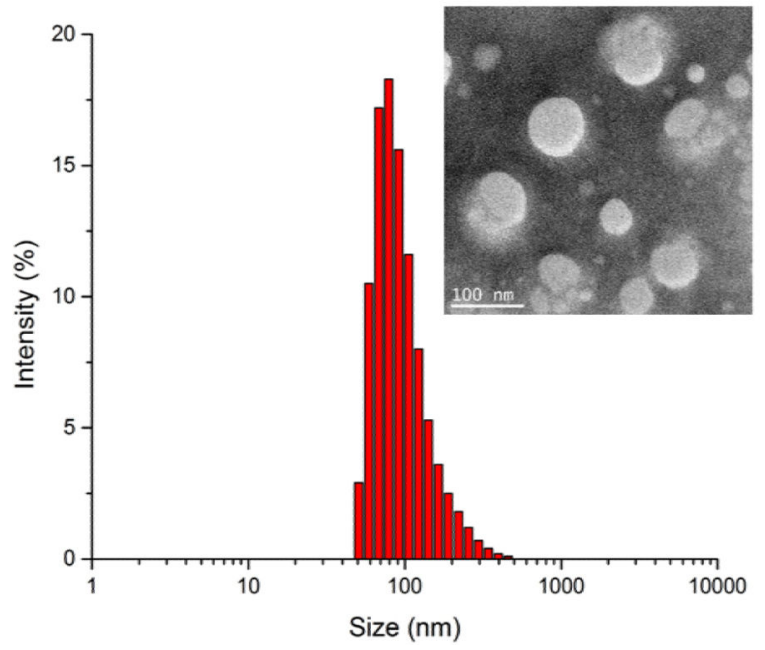

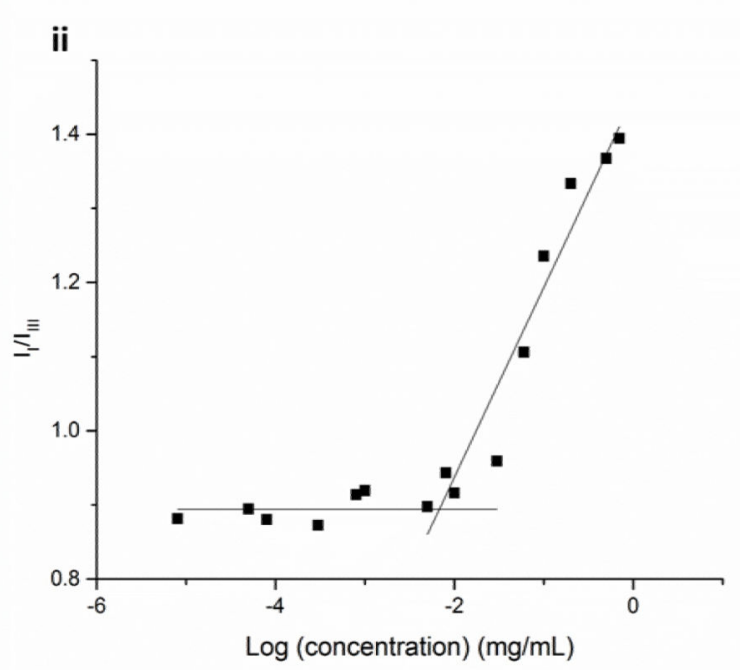

ii

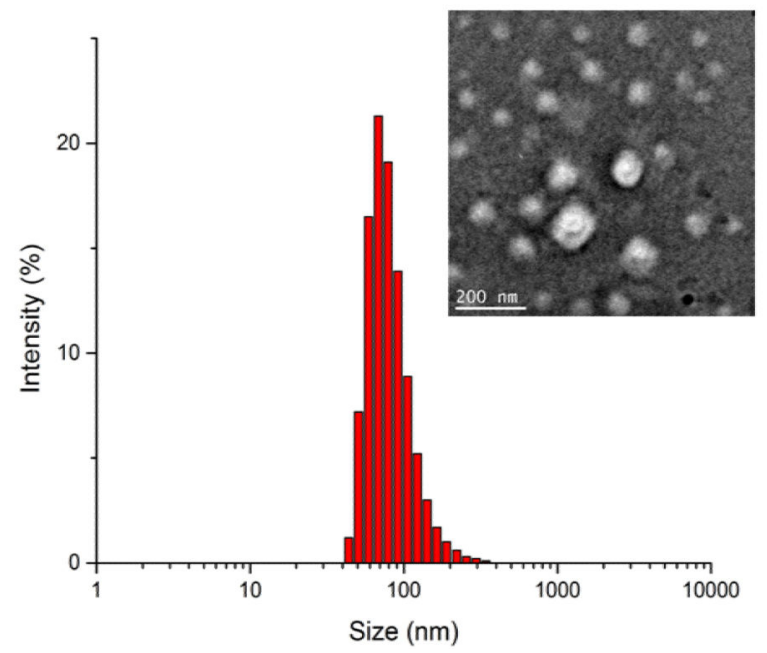

Fig. 5.

(A) Plot of the intensity ratio $\left(\mathrm{I}_{\mathrm{I}} / \mathrm{I}_{\mathrm{III}}\right)$ versus concentration of ACV-tagged polymeric micelles, and (B) particle size distribution of (i) ACV-PCL-MPEG and (ii) ACV-PCLchitosan. Insets represent TEM images. 


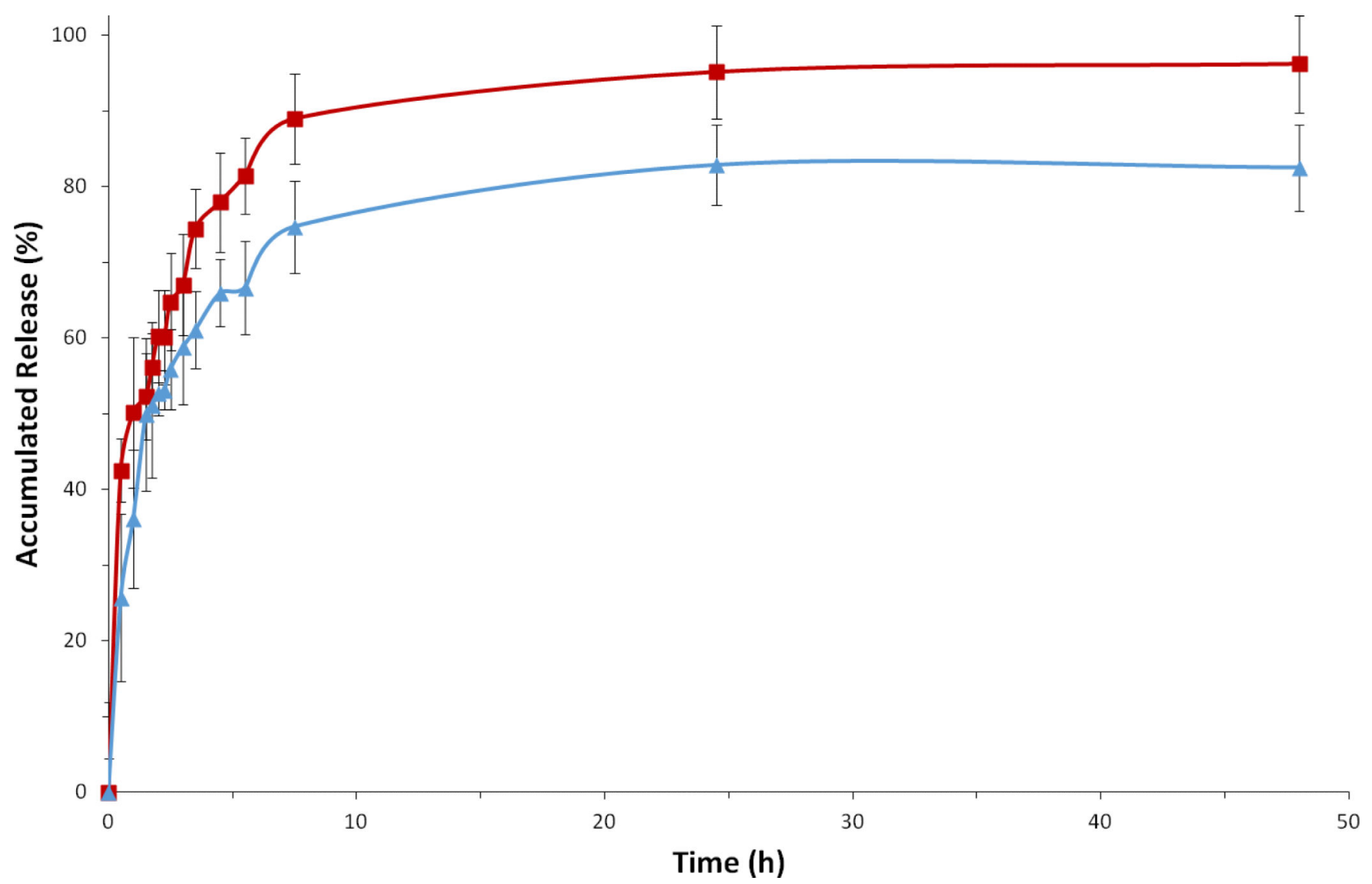

Fig. 6.

In vitro drug release profiles of ACV-PCL-MPEG ( $-\longrightarrow)$ and ACV-PCL-chitosan $(-\mathbf{m})$ polymeric micelles in PBS (mean $\pm \mathrm{SD}, n=3$ ). 


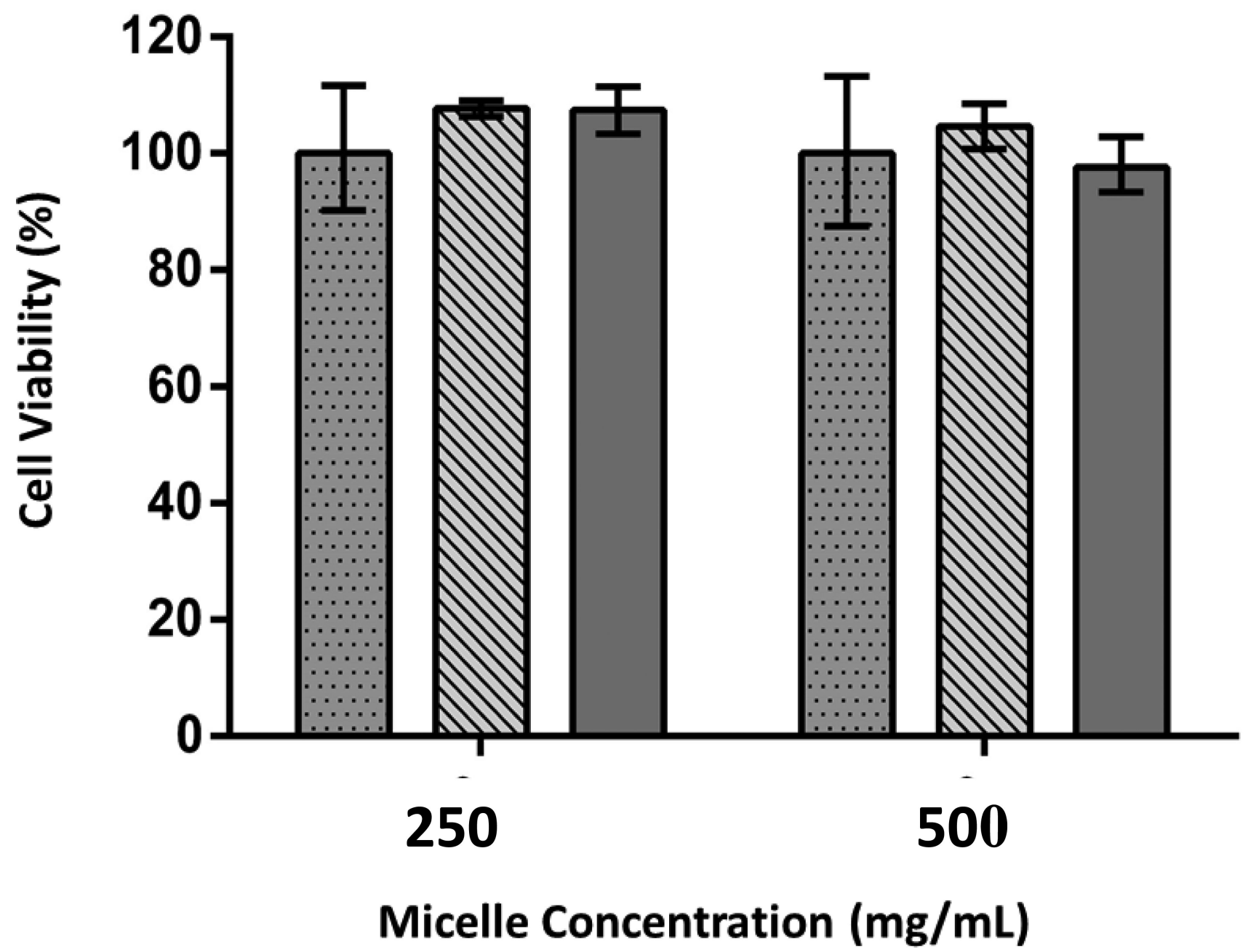

Fig. 7.

Viability of HT29 colorectal cancer cells challenged with ACV-tagged polymeric micelles at different dosages. and $\square$ ACV-PCL-chitosan micelles (mean $\pm \mathrm{SD}, n=3$ ). 